\title{
RECURSOS DIDÁTICOS NA EDUCAÇÃO MATEMÁTICA: JOGOS E MATERIAIS MANIPULATIVOS
}

\section{EDUCATIONAL RESOURCES IN MATHEMATICS EDUCATION: GAMES AND MANIPULATIVE AIDS}

\section{Regina Célia Grando}

Universidade Federal de São Carlos

E-mail: regrando@yahoo.com.br

\section{Resumo}

O propósito desse texto é discutir as contribuiç̧̃̃es que os recursos didáticos podem oferecer à Educação Matemática das crianças, jovens e adultos das escolas. Apresentamos o que entendemos por recursos didáticos em Educação Matemática e dois desses recursos: os materiais manipulativos e os jogos. Inicialmente discutimos cada um desses recursos e suas contribuições para a Educação Matemática nas escolas e, em seguida, focamos a atenção nos jogos computacionais como um recurso didático. O texto apresenta uma experiência de pesquisa com o uso de jogo computacional em aula de matemática evidenciando uma metodologia de trabalho com jogos na perspectiva da resolução de problemas. O foco se dá no processo de produção de uma escrita matemática articulada à ação no jogo computacional.

Palavras-chave: recursos didáticos. jogos computacionais. materiais manipulativos.

\begin{abstract}
The purpose of this paper is to discuss the contributions that can offer teaching resources for mathematics education of children, youth and adults in schools. We present what we mean by teaching resources in mathematics education and two of these features: games and manipulative aids. Initially we discuss each of these features and their contributions to mathematics education in schools and then focus attention on computer games as a teaching resource. The paper presents a research with the use of computer game in math class showing a working methodology with games from the perspective of problem solving. The focus is given in the production process of an articulated mathematical writing to action in the computer game.
\end{abstract}

Palavras-chave: teaching resources. computer games. manipulative aids. 


\section{INTRODUÇÃO}

O propósito desse texto é discutir as contribuições que os recursos didáticos podem oferecer

à Educação Matemática das crianças, jovens e adultos das escolas. Cabe, inicialmente, apresentarmos o que entendemos por recursos didáticos em Educação Matemática para, em seguida apresentarmos alguns desses recursos, com ênfase ao jogo computacional.

Os recursos didáticos são entendidos como modelos concretos ou não, que possam contribuir e facilitar a aprendizagem matemática dos alunos das escolas. Optei por apresentar nesse texto dois desses recursos: os materiais manipulativos e os jogos. Inicialmente discuto cada um desses recursos e suas contribuições para a Educação Matemática nas escolas e, em seguida, foco a atenção nos jogos computacionais como um recurso didático. Com relação aos jogos computacionais, apresento um recorte de uma dissertação de mestrado ${ }^{1}$ que desenvolve um trabalho pedagógico com jogos computacionais em aulas de matemática em um 9o ano do Ensino Fundamental em uma escola pública.

\section{AS “AJUDAS MANIPULATIVAS”: OS MATERIAIS MANIPULATIVOS}

A utilização de materiais de manipulação para o desenvolvimento dos conceitos matemáticos é apontada por Behr et al $(1983$, p.121) como um importante recurso para a simulação de situações de resolução de problemas. Os autores discutem que esse tipo de "ajuda manipulativa", como eles tratam os materiais de manipulação, tem se pautado de maneira restrita para a aprendizagem inicial ou retenção em curto prazo, considerando-os como uma ajuda inicial ou mesmo motivacional. Dessa forma, indicam a necessidade de novas experiências e pesquisas que investiguem o papel da manipulação de materiais na modelação de situações-problema do mundo real. Neste sentido, apontam:

1 GOMIDE, Cristiane G.S. O processo metodológico de inserção de jogos computacionais em sala de aula de Matemática: possibilidades do movimento de ação e reflexão da professora-pesquisadora e dos alunos. Dissertação (Mestrado em Educação) - Universidade São Francisco, Itatiba, SP, 2012. 
Os materiais manipulativos são um intermediário entre as situaçõesproblema do mundo real e do mundo das ideias abstratas e os símbolos escritos. Eles representam os símbolos em que podem ser usados para representar algumas situações diferentes de mundo real, sendo que são concretos, no qual envolvem materiais reais (p.122).

Na pesquisa realizada em Behr et al (1983) os materiais manipulativos tiveram destaque por facilitar a aquisição e uso de conceitos de número racional, quando ressaltaram a compreensão das crianças ao simular situações concretas a fim de compreender conceitos matemáticos abstratos. Apontam ainda as análises psicológicas que mostram que a manipulação é uma componente principal no desenvolvimento de sistemas representacionais e que a habilidade em fazer traduções entre os vários sistemas de representação tornam as ideias mais significativas para as crianças. Segundo Behr et al (1983) os materiais manipulativos oferecem um mecanismo capaz de libertar o processo de pensamento das crianças visto que a compreensão de uma situação particular numa sequência de atividades com materiais manipulativos podem contribuir para uma contínua reconstrução das condições do problema e podem permitir uma dinâmica de interação entre a resolução e as condições do problema.

Entendemos que há uma necessidade de se compreender que o uso de materiais manipulativos possibilita aos alunos uma visualização e uma possibilidade de representação de relações matemáticas que algumas vezes desejamos, enquanto professores, que o aluno compreenda. O seu uso não se justifica, somente, por envolver os alunos e motivá-los à aprendizagem, mas mobilizá-los a estabelecer relações, observar regularidades e padrões, pensar matematicamente. Por exemplo, o uso articulado do material dourado e do ábaco vertical para a aprendizagem das operações de adição e subtração nos anos iniciais do ensino fundamental contribui para a compreensão de dois aspectos fundamentais do sistema de numeração decimal: os agrupamentos em base 10 (material dourado) e o sistema posicional (ábaco vertical). As grandes críticas ao uso desses materiais nos anos iniciais dizem respeito ao mau uso desses, na medida em que apenas um deles era utilizado. A necessidade de se 
fazer o uso articulado dos dois materiais é a contribuição para uma melhor compreensão dos principais aspectos do sistema de numeração decimal, importantes para o cálculo. Ao manipular tais materiais, orientados por uma sequência de ensino proposta intencionalmente pelo professor, as crianças podem visualizar durante a manipulação do material, relações de agrupamento em base 10 (trocas entre cubinhos, barras, placas, etc.) e compreender, por exemplo, com o ábaco, o significado do "vai um" no algoritmo da adição (vai uma dezena, vai uma centena, etc.).

Os algoritmos das operações necessitam estar associados ao tipo de manipulação, assim para fazer $36+28$ usando material dourado, realizam-se os seguintes agrupamentos e o algoritmo associado é o da decomposição:

Figura 1. Adição usando o material dourado.
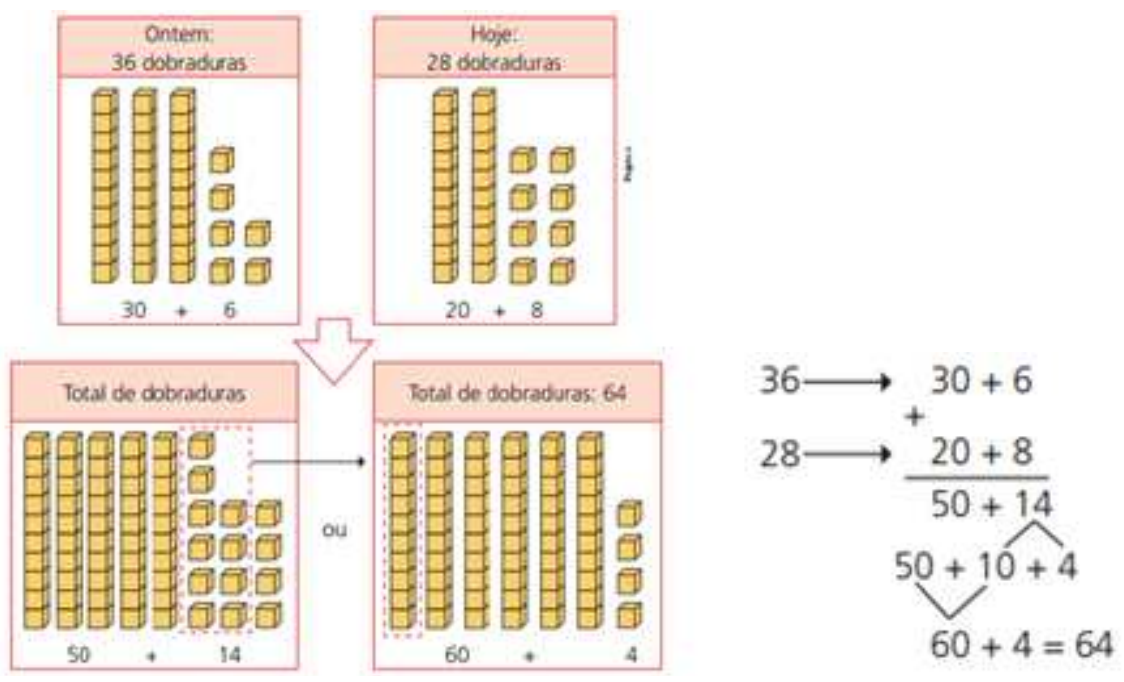

Fonte: Livro didático Matemática em seu tempo (GRANDO et al, 3ํano, p. 80-81).

Da mesma forma, o algoritmo associado à manipulação no ábaco é o convencional que prioriza o valor posicional do número. Para fazer 24 mais 18 no ábaco vertical: 
Figura 2. Adição usando o ábaco vertical.
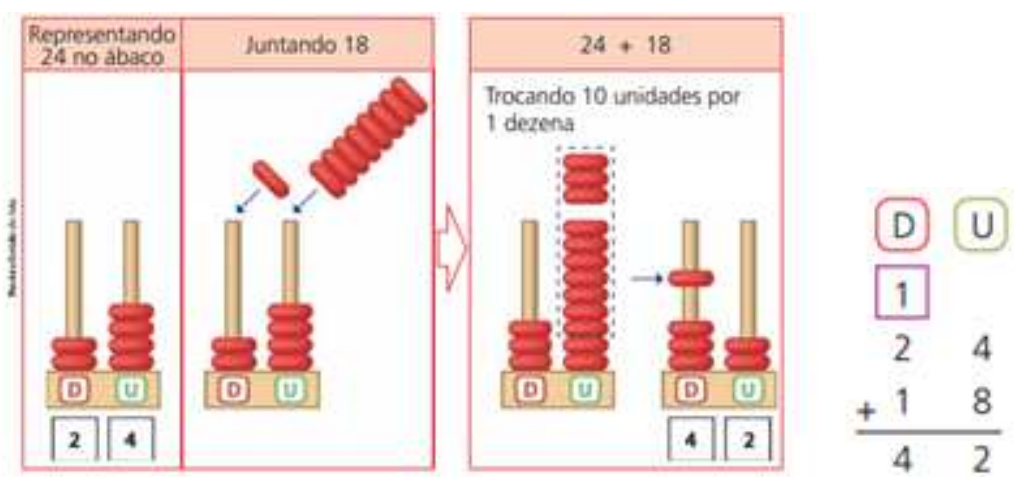

Fonte: Livro didático Matemática em seu tempo (GRANDO et al, 3ำ ano, p. 80-81).

Por outro lado, há que se considerar que qualquer material que se utiliza para "facilitar" a compreensão do aluno é necessário não oferecer um modelo mais complicado do que o próprio conceito, ou ainda, que ofereça um conhecimento errôneo, equivocado. Por exemplo, o uso do material dourado para se trabalhar com o conceito de décimos, centésimos e milésimos, sendo o cubo grande a unidade leva ao conceito errôneo de que não existem objetos concretos que represente, por exemplo, uma dízima como 1,3333... . Nesse caso, pode-se criar um obstáculo à compreensão da densidade do conjunto dos números racionais.

Post (1981) defende que a relação de simulação entre o material manipulativo e o conceito matemático necessita ser isomórfica, em que seria possível trabalhar no sistema mais simples ou mais adequado (material manipulativo) e transferir as conclusões ao sistema menos acessível, simbólico (conceito matemático). Isso só é possível se a estrutura de ambos os sistemas se mantiverem. Na verdade, os materiais de manipulação podem ser vistos como estruturas isomórficas, representando as noções matemáticas mais abstratas que se deseja que as crianças aprendam. A manutenção do isomorfismo é a base para a seleção do material a ser utilizado.

$\mathrm{Na}$ realidade, isomorfismos completos nunca existem realmente entre um conceito abstrato e um conjunto de materiais físicos ou uma situação real. 0 isomorfismo parcial se aproxima do conceito tanto quanto a estrutura mais 
acessível seja útil no ensino desse conceito. $\mathrm{O}$ fato de alguns conjuntos de materiais de manipulação ser melhores que outros para ensinar determinados conceitos comprovam isso (POST, 1981, p.3).

O importante é garantir, na seleção do material, um conhecimento quanto às limitações e possibilidades de cada tipo de material, inclusive sem a pretensão de acreditar que o seu uso seja suficiente para a compreensão, pelo aluno, de um determinado conceito. Essa compreensão está baseada nas relações e interações propiciadas pela ação didática do professor que envolve seu planejamento, a problematização, a observação de regularidades, a generalização e a sistematização do conceito por meio de uma linguagem propriamente da matemática.

\section{OS JOGOS COMO RECURSOS DIDÁTICOS NA EDUCAÇÃO MATEMÁTICA}

O uso de jogos como recursos para o ensino de matemática difere da simples manipulação de materiais. O jogo possui características próprias que dão a ele um status diferenciado. 0 jogo tem regras que necessitam ser respeitadas durante toda a partida, é necessário ficar claro quem é o vencedor ou se há um empate, tem um movimento (começo, meio e fim) e isso lhe garante uma ordem, além de ser uma atividade voluntária.

O uso pedagógico do jogo necessita garantir suas principais características, embora a voluntariedade nem sempre seja respeitada. Acreditamos que há duas formas de se propor o uso de jogos em aulas de matemática: uma delas em que o professor, ao planejar desenvolver um determinado conteúdo, cria um jogo ou busca algum já existente, que foi criado com o objetivo de ensinar matemática (dominó das formas, da tabuada, bingo das operações, etc.); e outro em que o professor busca na atividade lúdica de seus alunos, jogos de entretenimento, que foram criados com esse fim ou ainda jogos criados para passatempo em uma determinada cultura e planeja uma ação intencional a fim de explorar, também, a matemática a partir desse jogo, uma matemática que possibilita dar sentido à estratégia do jogo. 
Nesse último caso o jogo é considerado o "conteúdo de ensino" e o conhecimento matemático a partir do jogo possibilita ao aluno melhorar sua atuação no jogo. Esse jogo é mais interessante do ponto de vista do interesse do aluno - porque é um jogo de entretenimento que faz parte de uma cultura lúdica - e porque os alunos atribuem um sentido à aprendizagem matemática: jogar bem. Esses jogos, na maioria das vezes, são de estratégia e possibilitam a elaboração de procedimentos vencedores. A matemática se encontra impregnada em tais estratégias, procedimentos. Interessa-nos esse segundo tipo de jogos, uma vez que se propõe um trabalho pedagógico com jogos na perspectiva da resolução de problemas.

Os jogos de estratégia utilizados no ensino de Matemática são aqueles em que se desenvolve um ou vários procedimentos típicos de resolução de problemas ou os modos habituais de pensamento matemático. Segundo Corbalán (1996) são importantes para a formação do pensamento matemático dos alunos e propiciam caminhos para a generalização. Os professores, algumas vezes, apresentam muita resistência para utilizá-los, tendo dificuldade para definir os objetivos da atividade com esse tipo de jogo, entretanto são bem aceitos pelos alunos. Para os pais esses jogos são pouco sérios, já que não compreendem os objetivos. Seus resultados não são imediatos, o que dificulta na avaliação tradicional (CORBALÁN, 1996).

Desta forma, poderíamos dizer que esse tipo de jogo propicia o desenvolvimento de estratégias de resolução de problemas na medida em que possibilita a investigação, ou seja, a exploração do conceito através da matemática possível a partir do jogo e que pode ser vivenciada, pelo aluno, quando ele joga, elabora estratégias, analisa-as a fim de vencer o jogo. O cerne da resolução de problemas está no processo de elaboração de estratégias, levantamento de hipóteses, problematização, registro e análise/validação de resoluções. No jogo ocorre fato semelhante. Ele representa uma situação-problema determinada por regras, em que o indivíduo busca a todo o momento, elaborando estratégias, procedimentos e 
reestruturando-os, vencer o jogo, ou seja, resolver o problema. Esse dinamismo característico do jogo é o que possibilita identificá-lo no contexto da resolução de problemas.

A maioria das brincadeiras infantis ou mesmo dos jogos corporais podem ser momentos propícios a uma exploração também matemática da brincadeira. Na ação as crianças podem experimentar o espaço em que a brincadeira ocupa ou as regras (amarelinha, boliche, mãe da rua, gude, etc.). No registro elas podem "pensar sobre uma ação vivenciada" e dar a sua interpretação. Nesses registros, muitas vezes, evidenciam um registro matemático. Por exemplo, uma criança de três anos fez o seguinte registro da brincadeira de amarelinha:

Figura 3. Registro da amarelinha.

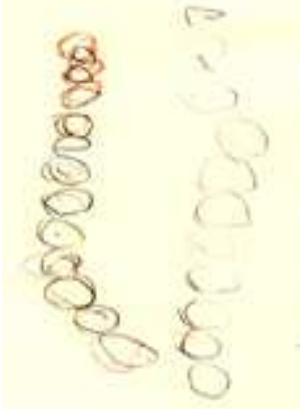

Fonte: arquivo da pesquisadora.

Olhando para esse registro fica difícil imaginar o que a criança desenhou. Mas conversando com ela e contando quantas bolinhas ela fez, identificamos uma quantificação. Há exatamente a mesma quantidade de bolinhas e de alunos que participaram da atividade. Isso evidencia que a criança comunicou, por meio de uma linguagem (desenho), uma representação numérica: a quantidade de alunos na brincadeira. Dessa forma, no registro a criança prioriza quais elementos foram importantes na brincadeira e, dentre vários possíveis: movimento, representação dos símbolos numéricos, crianças brincando, o espaço da brincadeira etc, ela preferiu quantificar.

Em Grando $(1995,2000,2004)$ defendemos a inserção dos jogos no contexto educacional numa perspectiva de resolução de problemas. Partimos do pressuposto de que o processo 
desencadeado pelo jogo é semelhante ao desenvolvido na resolução de um problema, embora, na situação de jogo, o problema se apresente dinâmico, ou seja, como um problema em movimento (MOURA, 1994). Assim sendo, o jogo, nessa perspectiva, insere-se numa interpretação de resolução de problemas (MENDONÇA, 1993) que considera o problema como ponto de partida para a aprendizagem matemática.

Vários fatores de ordem metodológica necessitam ser explorados pelo professor e fazer parte de seu plano de ação pedagógica. Estes fatores caracterizam-se por algumas condições necessárias para o surgimento dos jogos no contexto escolar.

Por exemplo, o ambiente da sala onde serão desencadeadas as ações com jogos, necessita ser planejado, propício à investigação, principalmente se se tratar de crianças, de forma que, ao trabalharem em grupos, eles possam criar novas formas de se expressar, com gestos e movimentos diferentes dos normalmente "permitidos" numa sala de aula tradicional. É necessário que seja um ambiente onde se possibilitem momentos de diálogo sobre as ações desencadeadas. Um diálogo entre alunos e entre professor e aluno, que possa evidenciar as formas e/ou estratégias de raciocínio que vão sendo utilizadas e os problemas que vão surgindo no decorrer da ação.

O conceito matemático vai sendo explorado na ação do jogo e mediação do professor e dos colegas uma vez que não basta jogar simplesmente para construir as estratégias e determinar o conceito. É necessária uma reflexão sobre o jogo, análise do jogo. Um processo de reflexão e elaboração de procedimentos para a resolução dos problemas que aparecem no jogo. Observando as regularidades presentes na ação do jogo, ou mesmo na resolução das situações-problema de jogo, é possível ao sujeito: ter previsões de jogadas, levantar hipóteses, corrigir "jogadas erradas" e elaborar estratégias vencedoras.

Poderíamos sintetizar os momentos/movimentos de jogo a serem considerados na realização das atividades de mediação com jogos em situações de sala de aula, que parecem ser 
relevantes para a prática pedagógica (GRANDO, 2000, 2004):

$1^{\circ}$ ) familiarização com o material do jogo: neste primeiro momento, os alunos entram em contato com o material do jogo, identificando materiais conhecidos, como: dados, peões, tabuleiros e outros, e experimentam o material através de simulações de possíveis jogadas. É comum o estabelecimento de analogias com os jogos já conhecidos pelos alunos;

$2^{\circ}$ ) reconhecimento das regras: o reconhecimento das regras do jogo, pelos alunos, pode ser realizado de várias formas: explicadas pelo orientador da ação ou lidas ou, ainda, identificadas através da realização de várias partidas-modelo, onde o orientador da ação pode jogar várias partidas seguidas com um dos alunos, que aprendeu previamente o jogo, e os alunos restantes tentam perceber as regularidades nas jogadas e identificam as regras do jogo;

$3^{\circ}$ ) o "jogo pelo jogo"/ jogar para garantir regras: este é o momento do jogo pelo jogo, do jogo espontâneo simplesmente, em que se possibilita ao aluno jogar para garantir a compreensão das regras. Neste momento, são exploradas as noções matemáticas contidas no jogo. Joga-se para garantir que as regras tenham sido compreendidas e que vão sendo cumpridas;

$4^{\circ}$ ) intervenção pedagógica verbal: os alunos passam a jogar agora contando com a intervenção propriamente dita. Trata-se das intervenções que são realizadas verbalmente, pelo orientador da ação, durante o movimento do jogo. Este momento caracteriza-se pelos questionamentos e observações realizadas pelo orientador da ação a fim de provocar os alunos para a realização das análises de suas jogadas (previsão de jogo, análise de possíveis jogadas a serem realizadas, constatação de "jogadas erradas" realizadas anteriormente, etc.). Neste momento, a atenção está voltada para os procedimentos criados pelos sujeitos na resolução dos problemas de jogo, buscando relacionar este processo à conceitualização matemática; $5^{\circ}$ ) registro do jogo: é um momento que pode acontecer, dependendo da natureza do jogo que é trabalhado e dos objetivos que se têm com o registro. $\mathrm{O}$ registro dos pontos, ou mesmo dos procedimentos e cálculos 
utilizados, pode ser considerado uma forma de sistematização e formalização, através de uma linguagem própria que, no nosso caso, seria a linguagem matemática. É importante que o professor procure estabelecer estratégias de intervenção que gerem a necessidade do registro escrito do jogo, a fim de que não seja apenas uma exigência, sem sentido para a situação de jogo. O registro é um importante instrumento de que pode dispor o aluno, para a análise de jogadas e construção de estratégias;

$6^{\circ}$ ) intervenção escrita: trata-se da problematização de situações de jogo. Os alunos resolvem situações-problema de jogo, elaboradas pelo professor ou mesmo propostas pelos colegas. A resolução dos problemas de jogo propicia uma análise mais específica sobre o jogo, onde os problemas abordam diferentes aspectos do jogo que podem não ter ocorrido durante as partidas. Além disso, trata-se de um momento onde os limites e as possibilidades do jogo são resgatados pelo professor, direcionando para os conceitos matemáticos a serem trabalhados (aprendizagem matemática). 0 registro do jogo também está presente, neste momento. Para o aluno, as situações-problema escritas representam uma análise sobre as suas formas de jogar, o que significa em uma melhora do seu desempenho a fim de vencer o jogo;

$7^{\circ}$ ) jogar com "competência": um último momento representa o retorno à situação real de jogo, considerando todos os aspectos anteriormente analisados (mediações). É importante que o aluno retorne à ação do jogo para que execute muitas das estratégias definidas e analisadas durante a resolução dos problemas. Optou-se em denominar este momento por "jogar com competência", considerando que o aluno, ao jogar e refletir sobre suas jogadas e jogadas possíveis, adquire certa "competência" naquele jogo, ou seja, o jogo passa a ser considerado sob vários aspectos e óticas que inicialmente poderiam não estar sendo considerados.

Apenas jogar um jogo tem pouca contribuição para a aprendizagem em matemática. É todo o processo de mediação realizado pelo professor, de discussão matemática realizado no grupo de alunos, de registro e sistematização de conceitos que possibilitam um trabalho efetivo 
com a matemática a partir do jogo.

O desconhecimento sobre a utilização de jogos em aulas de matemática pode levar a alguns equívocos. É importante garantir problematizações a partir do jogo e não sobre o jogo. Por exemplo:

Problemas sobre o jogo de boliche: quem venceu? Quantos pontos o vencedor fez? Em que essas questões contribuem para uma ação diferenciada para uma próximo jogo? Como é possível melhorar? Problemas a partir do jogo de boliche: a organização dos pinos do jogo interfere no resultado? Como organizar os dados para identificar o vencedor? O processo de intervenção representa "como" o professor pode interferir no desenvolvimento de conceitos e/ou habilidades matemáticas pelo aluno (você fez uma boa jogada? Por quê? Quais opções de jogadas você tem? Será que a sua estratégia sempre dá certo? Incentivar: jogar pensando alto, análise de jogadas, antecipações, etc.). A observação define "o quê" o professor pode observar durante as ações dos alunos no jogo (o aluno demonstra interesse pelo jogo? Estabelece relações entre as partidas? Observa regularidades e elabora estratégias? Demonstra reconhecer as "jogadas erradas"? Levanta hipóteses? A ação do aluno no jogo é intencional, planejada?).

Nosso objetivo de forma alguma é oferecer um modelo descritivo, ou mesmo etapas para se desenvolver um trabalho pedagógico com jogos, mas oferecer uma reflexão ao professor no sentido de compreender que o jogo, enquanto recursos didático, necessita ser problematizado e essa ação não é realizada pelo próprio jogo, mas pelo professor que tem uma intenção ao levar o jogo para a sala de aula.

\section{JOGOS COMPUTACIONAIS: DESAFIOS AOS PROFESSORES PARA A APRENDIZAGEM MATEMÁTICA}

Os jogos computacionais passam cada vez mais a fazer parte da cultura lúdica de crianças e 
jovens. Eles existem no mercado em uma variabilidade de formas, objetivos e ações a serem realizadas. São criados para entretenimento e respeitam uma linguagem e lógica próprias dos jogos computacionais, que são, na maioria das vezes, compreendidas pelos alunos e desconhecida pelos professores. As pesquisas que orientamos (MENDES, 2006; PACHECO NETO, 2008, ANDRADE, 2009, GOMIDE, 2012) tomaram o jogo computacional como recurso didático na Educação Matemática de adolescentes e jovens.

Esse conjunto de pesquisas evidencia que é necessário ter cautela quanto ao tipo de jogo, quanto à proposta de intervenção e quanto à análise efetiva sobre quais contribuições que tais jogos podem oferecer à aprendizagem matemática. Uma delas, sem dúvida, é a tomada de decisão rápida. A escola tem se pautado em garantir aos alunos momentos e ritmos próprios de aprendizagem. Entretanto, nem sempre esse tempo pode ser respeitado. Em alguns momentos, a tomada de decisões precisa ser rápida e, nesse caso, as estimativas e aproximações são mais importantes do que o cálculo exato. Essa é uma habilidade que a maioria dos jogos computacionais possibilita aos alunos e que pouco está presente na escola. Além dessas, muitas outras habilidades e diferentes formas de compreensão sobre um problema matemático podem ser exploradas na ação e análise de jogos computacionais.

Como exemplo, podemos citar a pesquisa de Gomide (2012). O objetivo da pesquisa foi investigar como a inserção de jogos computacionais em aulas de matemática pode possibilitar um movimento de ação e reflexão da professora pesquisadora e dos alunos dos anos finais do Ensino Fundamental, numa perspectiva de resolução de problemas. A autora desenvolveu três jogos computacionais com seus alunos do 9o ano do Ensino Fundamental em aulas de matemática. Ela explicita no trabalho que, em um primeiro momento, tinha a intenção de desenvolver sua pesquisa com jogos de tabuleiro. Entretanto, como professora da rede pública de ensino de uma cidade no interior de São Paulo, ao chegar ao início do ano à sua sala de aula, todas as lousas de giz tinham sido removidas e substituídas por lousas digitais, ligadas a um computador e todos os alunos receberam um NET (semelhante a um mini notebook), com alguns programas já implantados. A orientação 
foi que, a partir daquele momento, as aulas deveriam ser preparadas com o uso de tais tecnologias. A professora pesquisadora, inicialmente, se viu sem orientação e preocupada com os rumos da pesquisa. Decidimos (fui a orientadora do trabalho), então, que ela mudaria seu objeto de estudo na pesquisa e passaria a trabalhar com os jogos computacionais. Para tanto, realizamos inicialmente um levantamento com os alunos sobre quais tipos de jogos computacionais eles estavam mais habituados a jogar. Para esse levantamento os alunos responderam ao seguinte questionário aberto:

Que tipo de jogos computacionais você costuma praticar em sua casa?

O que mais lhe chama a atenção nesse(s) jogo(s)?

Como eu (professora-pesquisadora) poderia encontrar este jogo? É comprado? Se

for, como poderia adquiri-lo?

Se for gratuito, em que site poderia conhecê-lo?

Você indicaria este jogo para que eu jogasse em minha casa? Por quê?

A grande maioria preferia os jogos de simulação e de aventura. Conhecemos alguns jogos e analisamos as possibilidades de exploração de conteúdos matemáticos a partir do jogo. Os dados foram produzidos por meio de registro em diário de campo da pesquisadora, registros de jogos dos alunos e audiogravações dos momentos de jogo. Um dos jogos desenvolvidos foi o Yellowout.

Figura 4. Tela inicial do jogo.

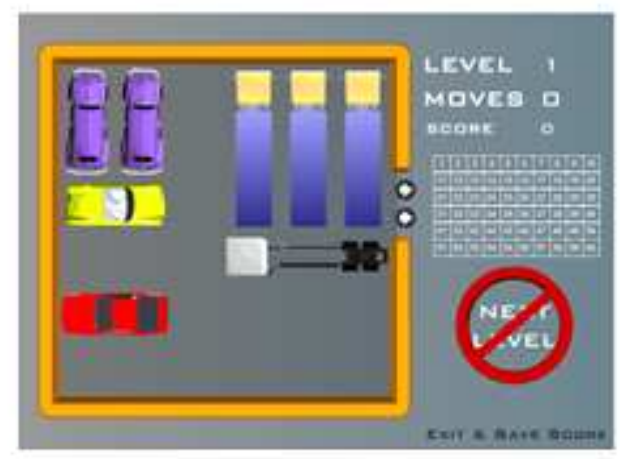

Fonte: GOMIDE, 2012, p.127. 
O jogador deve movimentar os carros, as carretas e os caminhões, para frente e para trás, quantas vezes desejar, para "liberar" o carro amarelo para que ele possa sair do estacionamento. A cada nova jogada há uma tela diferente de jogo, mais complexa. Nesse jogo há uma relação de medida entre o tamanho dos carros, das carretas e dos caminhões. 0 aluno, ao perceber tal relação, pode chegar mais rapidamente às estratégias de resolução dos problemas de jogo. Para que essa relação seja observada a professora-pesquisadora sugere que os alunos criem uma linguagem própria para a comunicação de suas resoluções para o problema do jogo a fim de analisar tais registros. Nesse momento a pesquisadora escreve em seu diário de campo:

Pensando nos possíveis movimentos que os alunos poderiam realizar para alcançar o seu objetivo, propus aos alunos que procurassem transcrever de uma maneira fácil e simples de entender, como eles iriam retirar o carro amarelo do estacionamento. A intenção era fazer com que os alunos criassem uma linguagem na qual pudesse nos comunicar, afinal eu não estaria ao lado de todos ao mesmo tempo para que eles pudessem descrever o que eles estavam fazendo, como estavam pensando e como poderia ser detectado os erros e acertos, vindos de suas próprias reflexões (GOMIDE, 2012).

Os registros iniciais foram pouco satisfatórios e não comunicavam o processo de resolução. 
Figura 5. Registro inicial de jogo.

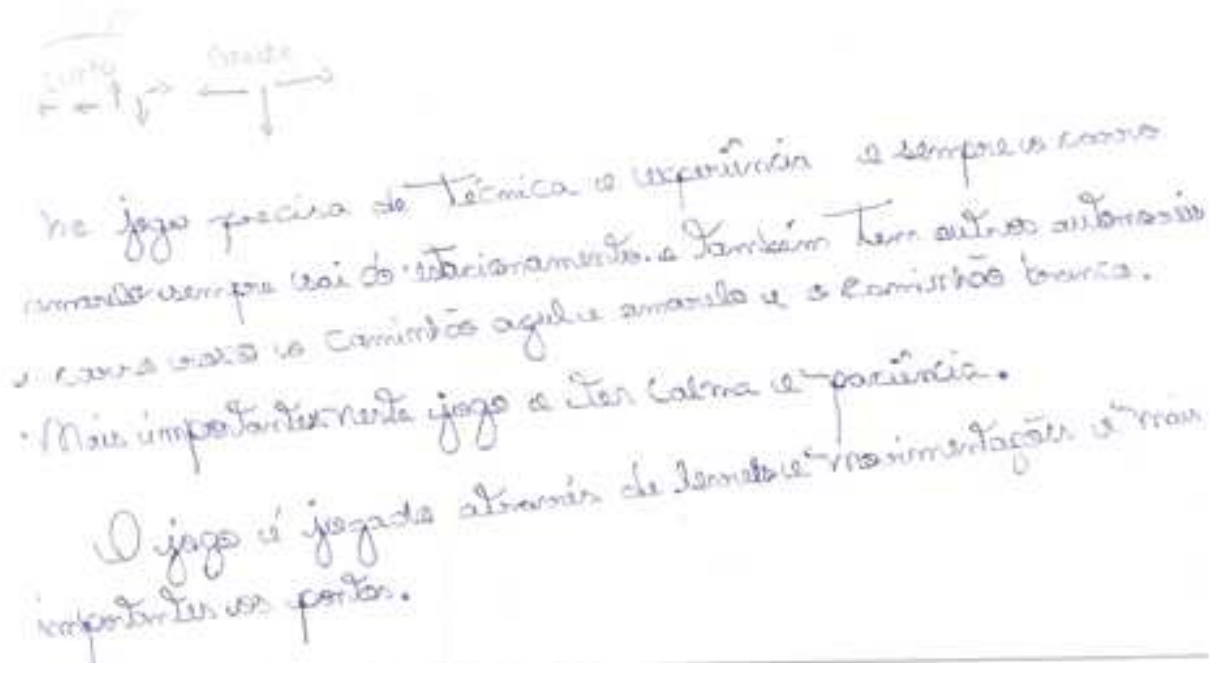

Fonte: GOMIDE, 2012, p.130.

no jogo precisa de técnica e experiência e sempre o carro amarelo sempre sai do estacionamento e também tem outros automóveis o carro roxo o caminhão azul e amarelo e o caminhão branco. Mais importante neste jogo é ter calma e paciência. O jogo é jogado através dos "leveis" e movimentações e mais importante os pontos. (transcrição)

O registro desse grupo nos fez pensar sobre o sentido que o registro estava tendo para os alunos naquele momento. Eles escreveram sobre o jogo e não o registro de jogo. Não fazia sentido essa comunicação. Nas práticas escolares poucos são os momentos em que os alunos são convidados a produzirem, criarem um registro de comunicação. A linguagem, na maioria das vezes está posta ou (im)posta. No caso dessa proposta os alunos necessitavam criar uma linguagem representativa do que estavam pensando. Esse tipo de linguagem assume o papel de registro, nesse caso, registro de jogo, que é diferente de um registro sobre o jogo. Durante a análise pudemos perceber, por meio desse registro dos alunos e de outros semelhantes, 
que a proposta do registro ainda não havia ficado clara para aqueles alunos.

A dificuldade era compreensível afinal os alunos nunca haviam realizado algo parecido nas aulas de Matemática. Escrever como se está pensando é um processo metacognitivo. Segundo Powell \& Bairral (2006) a escrita força os alunos a refletir e quando (re)lê suas próprias produções, possibilita desenvolver o senso crítico. Além do que, a escrita pode ajudar os alunos a tornar seu vocabulário mais rico e também a usarem-no no contexto da sua compreensão.

Pensando nessa perspectiva, concordamos com Mayher, Lester e Prado (1983 apud Powell \& Bairral, 2006, p. 27) ao que se refere ao aprendizado em geral:

A capacidade da escrita em colocar o educando no centro da sua própria aprendizagem pode e deve tornar-se um elemento facilitador importante na aprendizagem de tudo que envolva a linguagem. A escrita que envolve escolha de linguagem requer que quem escreve encontre as suas próprias palavras para expressar tudo que esteja a ser aprendido. Tal processo pode incialmente servir para a revelação de mais falhas do que compreensão do estudante numa determinada disciplina, mas mesmo isso pode ser de grande valor diagnóstico tanto para o professor como para o educando. E à medida que o processo se repete, adquire-se um domínio real e duradouro da disciplina e do seu vocabulário técnico.

A pesquisadora, então, intervém e discute com os alunos no sentido de evidenciar que aquele tipo de registro trazia poucas contribuições para o entendimento do processo de resolução do problema e sugere a criação de uma linguagem específica que evidenciasse a resolução: 
Figura 6. Reescrita do registro de jogo.

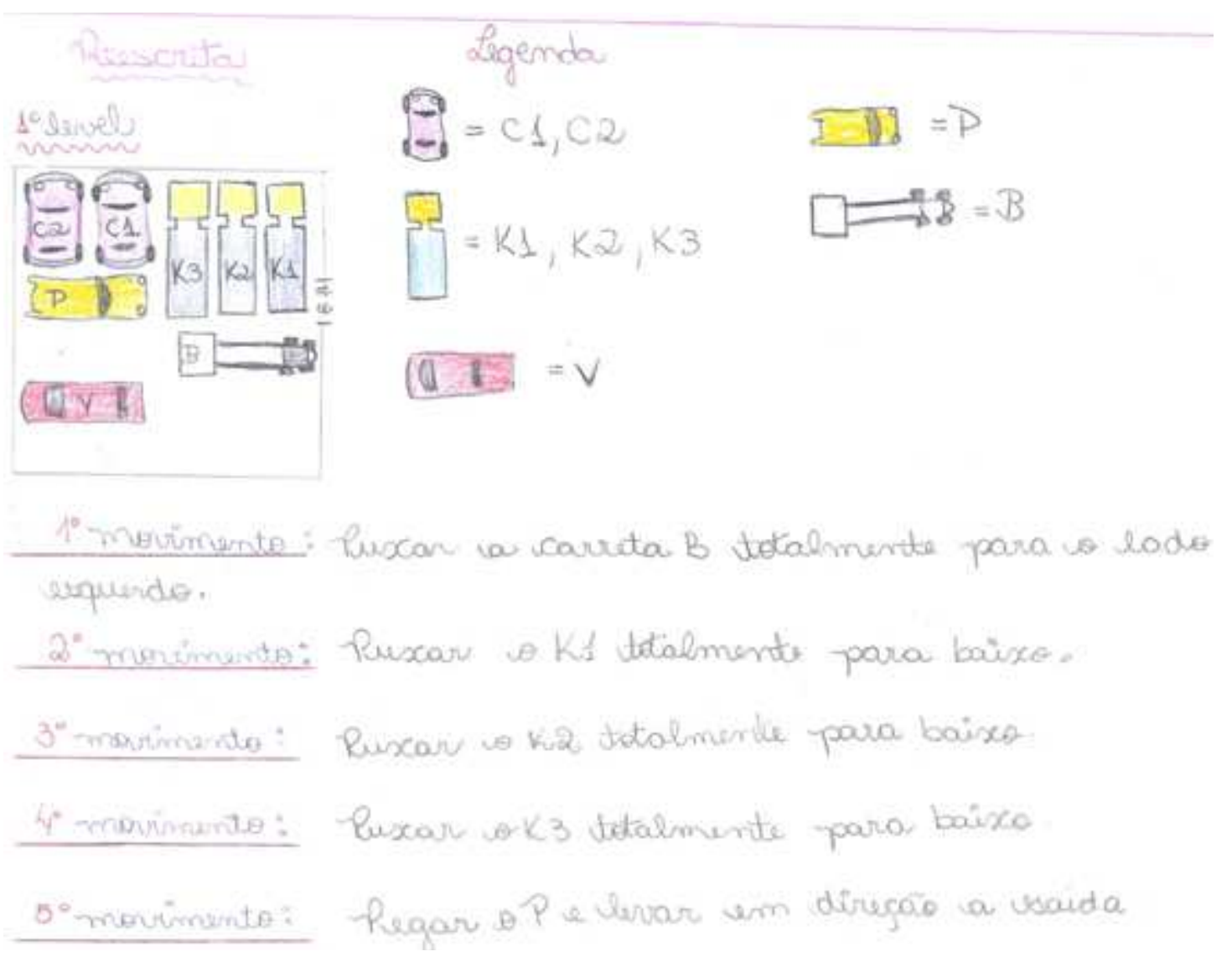

Fonte: GOMIDE, 2012, p. 136.

Vários elementos podem ser observados nesse segundo registro: a necessidade de uma legenda, a definição de procedimentos de resolução (1ำ movimento, 2o movimento, etc.), a identificação de cada veículo, etc. Nesse registro já se evidencia o uso do desenho, enquanto recurso de imagem, que auxilia na explicação da resolução do problema. O uso da legenda também era familiar aos alunos:

O grupo de J.A. afirmou que a escolha da escrita com números e letras seria, também, para facilitar a localização dos veículos citados em cada movimentação e que simplificaria muito, se quem fosse ler a resposta encontrada olhasse a legenda para depois ler a resposta encontrada por elas: "Hoje, se a gente pegar qualquer tipo de gráfico, eles mostram com cores o que significa cada cor no gráfico com a legenda, assim facilita para o leitor entender o que significam as linhas coloridas, fizemos então a mesma 
coisa..." (J.A. do grupo das meninas). O grupo estabeleceu uma analogia entre o tipo da escrita que produziram e outras formas de linguagem que identificam no cotidiano (GOMIDE, 2012, p. 137).

Além das situações de jogo, foram propostas situações-problema. A produção textual pelos alunos em situações de escrita e reescrita instrumentalizou-os para que pudessem resolver e comunicar os processos de resolução das situações-problema escritas. Descrevemos a seguir duas delas e a resolução pelos alunos:

Situação-problema 2: Nas três fases, quais movimentos, no mínimo, você consegue fazer para retirar o carro amarelo do estacionamento? Quantos movimentos foram necessários em cada fase?

Buscamos aqui proporcionar aos grupos que fizessem a análise em relação às três situações propostas. A primeira e a terceira figura possuem a mesma quantidade de veículos (12) e a segunda possui um veículo a menos (11). Assim, gostaríamos de verificar se os grupos observariam as situações a fim de identificar o que dificultaria a retirada do carro principal, que é o amarelo.

Figura 7. Situações de jogo.
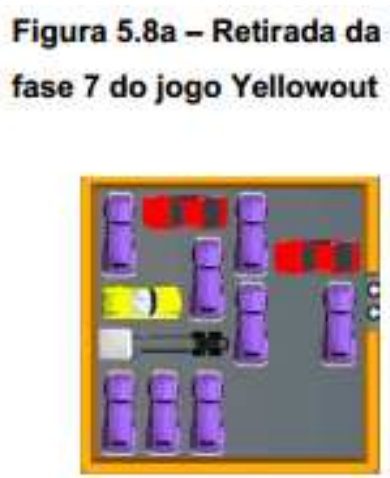

Fonte: Jogo Yellowout
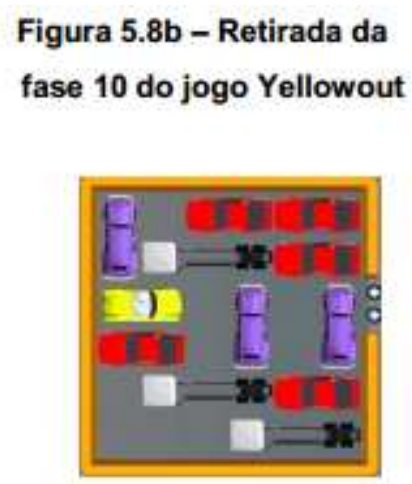

Fonte: Jogo Yellowout

\author{
Figura 5.8c - Retirada da \\ fase 8 do jogo Yellowout
}

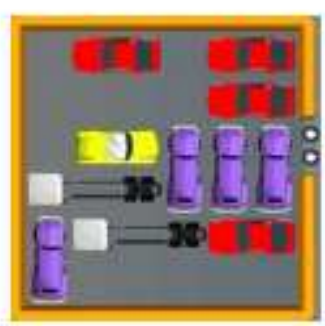

Fonte: Jogo Yellowout
Fonte: GOMIDE, 2012, p. 142. 
solução seria muito difícil, pois havia vários veículos e demoraria mais tempo para resolver; e que a quantidade de movimentos seria maior do que as que tinham poucos veículos. Entretanto, ao experimentar resolver o problema, deram conta rapidamente:

Figura 8. Resolução dos alunos.

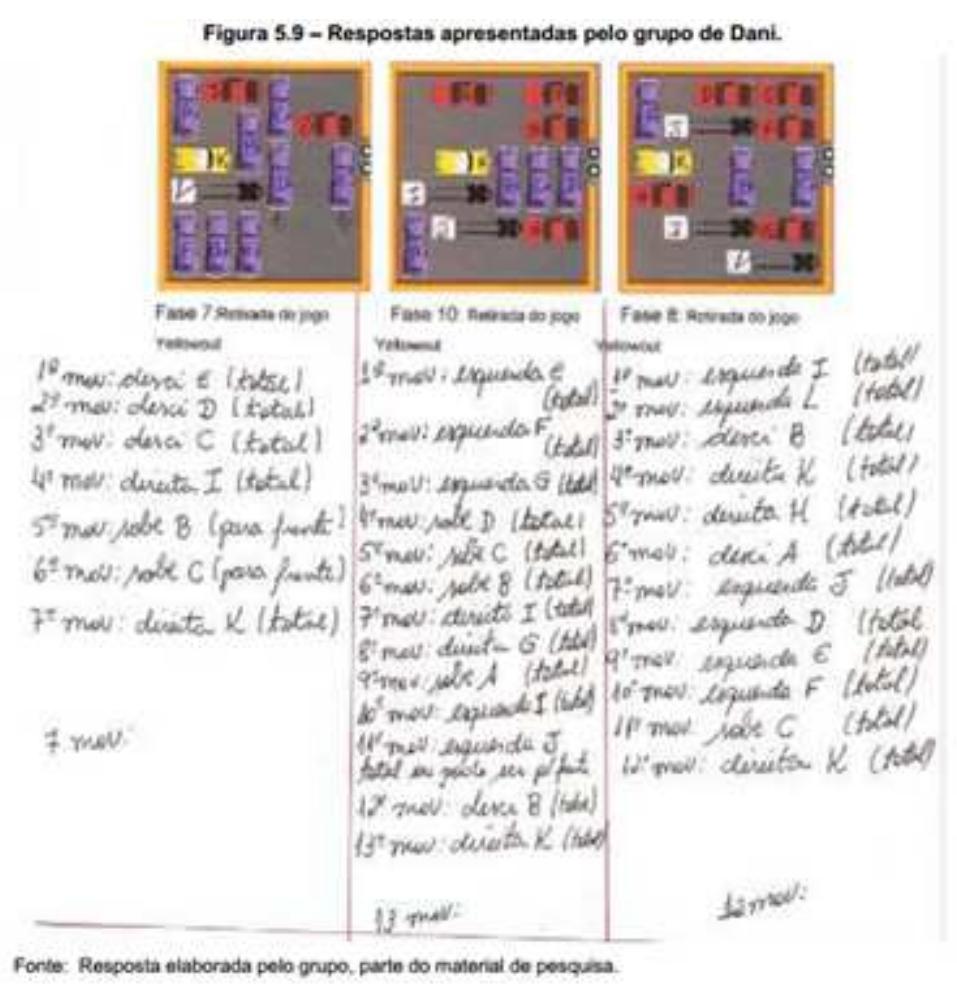

Fonte: GOMIDE, 2012, p. 143.

O nível de detalhes com que explicaram a movimentação do jogo evidenciou que, para eles, também era necessário registrar todos os movimentos, para que pudessem retomar, caso "se perdessem" na resolução. O registro, nesse sentido, assume também um papel de "um guardado" que possibilita ser revisitado para dar continuidade ao movimento, a partir de qualquer passo do jogo. Segundo Powell e Bairral (2006, p. 48), a reflexão sobre os atos mentais pode gerar representações para o aprendiz desenvolver maneiras mais eficazes de pensar. Esse processo facilita ao aluno buscar refletir sobre seus atos, encontrando soluções mais eficazes para o problema. Desde o início do jogo, quando aparecia uma situação com vários veículos, os grupos já diziam "essa vai ser difícil” e, quando havia poucos veículos, afirmavam "essa vai ser fácil". Mas a resolução da situação- 
problema evidenciou que não é a quantidade de veículos que determina, mas a sua disposição.

Outra situação-problema desenvolvida foi:

Situação-Problema 4: Se esse estacionamento estivesse com a lotação máxima, somente de carros, quantos caberiam? Como você pensou para responder o problema?

Figura 9. Resposta apresentada por um dos grupos.

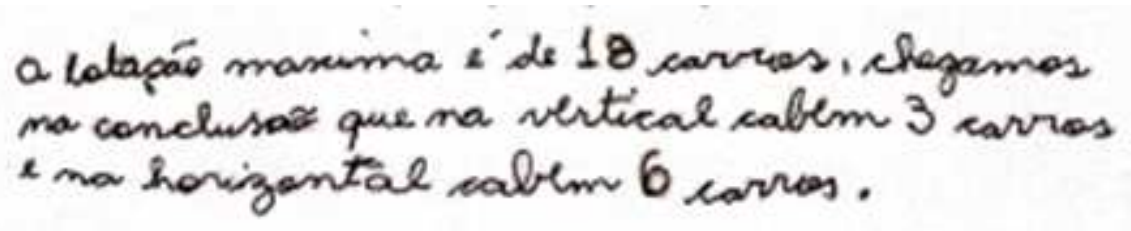

Fonte: GOMIDE, 2012, p. 154.

1. Pesquisadora.: E aí... qual foi a resposta encontrada pelo grupo?

2. Uli.: Bom.... foi essa aqui

3. Pesq.: E como foi que vocês pensaram para encontrá-la?

4. B.S.: Se a gente pegar a figura do primeiro-problema dá pra ter uma noção de quantos carros caberiam no estacionamento. É só pegar assim ô... Se na posição da vertical cabem 3 carros na horizontal cabem seis e que multiplicando 3 por 6 dá 18 carros.

Na fala (4) o aluno B.S. utiliza o processo multiplicativo para encontrar quantos carros caberiam no estacionamento. Enquanto refletia sobre sua resolução, mostrava para a professora-pesquisadora com os dedos as posições dos veículos sobre a folha contendo a situação-problema.

Foi de grande importância que os grupos começassem a analisar as posições dos veículos, sendo possível trabalhar com a noção de espaço. O grupo do Uli conseguiu verificar que a posição dos carros na vertical possibilitaria encontrar a quantidade de carros no 
estacionamento. A relação estabelecida entre a quantidade de carros nas colunas e linhas possibilitou o cálculo total de carros no estacionamento.

No trabalho desenvolvido com o jogo Yellowout pudemos investigar conceitos relativos ao espaço ocupado pelos veículos, deslocamentos nesse espaço, relações de proporcionalidade de tamanho dos veículos e as possibilidades de explicitação de resolução do problema por meio de uma linguagem elaborada por meio de códigos, legendas, desenhos, etc.

Além disso, foi possível explorar modos de pensar matematicamente característicos, como o levantamento de hipóteses, investigação, experimentação, análise de erros, reelaboração lógica do procedimento de resolução, etc. Assim, quando o aluno utilizou a escrita para transcrever seus pensamentos, ele teve a possibilidade de escrever e reescrever suas reflexões, construindo e reconstruindo um sentido para seus pensamentos, tornando possível expressar suas ideias com uma maior clareza e confiança. O aluno necessita ter a possibilidade de selecionar o tipo de linguagem que acha mais apropriada para descrever suas percepções e ações (POWELL e BAIRRAL, 2006) nas aulas de matemática.

Diferente da fala, a escrita é um meio estável que permite a alunos e professores examinarem colaborativamente o desenvolvimento do pensamento matemático (POWELL e BAIRRAL, 2006, p.27).

A interação entre os participantes foi fundamental, pois um ajudava o outro, criando possibilidades de resolução e analisando as hipóteses. O conhecimento não se situa apenas na experiência que o aluno faz, mas também nos atos mentais que são experimentados e que nesses estão os atos da reflexão.

Nesse sentido, entendemos que o jogo Yellowout trouxe contribuições significativas para os alunos do 9a ano do ensino fundamental, que estavam iniciando o estudo sobre funções.. 


\section{CONSIDERAÇÕES FINAIS}

A utilização de recursos didáticos nas aulas de matemática necessita ser intencionalmente planejada pelo professor e esse conhecedor dos limites e possibilidades de ação pedagógica de cada um desses recursos. Já sabemos que o simples manuseio de materiais não leva à aprendizagem, mas uma ação mediada e problematizada pelo professor. Há que se considerar se o recurso vem a facilitar, a oferecer uma ajuda manipulativa aos alunos, em vez de gerar um problema conceitual ou epistemológico.

Os resultados da pesquisa com jogos computacionais evidenciam as aprendizagens dos alunos no processo de construção de uma forma de produção de registros de jogo a fim de comunicar suas ideias matemáticas e as estratégias de resolução de problemas. Apontam, também, para a importância da pesquisa do professor sobre a sua prática, assim, ao refletir sobre suas ações, produz novos saberes com as experiências vividas, além do processo de ressignificação da própria prática pedagógica possibilitando o desenvolvimento profissional da professora que utiliza jogos computacionais nas aulas de matemática.

As pesquisas brasileiras sobre jogos computacionais e o ensino da Matemática ainda estão iniciando, entretanto já é possível sinalizar para as muitas contribuições que esse tipo de mídia pode oferecer à aprendizagem matemática e nos possibilita refletir sobre o adolescente que não tem um bom desempenho nas atividades escolares, mas desempenha brilhantemente sua ação no jogo. O desafio que se coloca às práticas pedagógicas dos professores é a incorporação desses novos recursos nas aulas de matemática.

\section{REFERÊNCIAS}

ANDRADE, K.F.Z. 0 jogo computacional Simcity no ambiente educacional de uma turma do Ensino Médio: saindo da "zona de conforto" almejando uma educação matemática crítica. Dissertação (Mestrado em Educação) - Universidade São Francisco, Itatiba, São Paulo, 2009. BEHR, Merlyn J.; LESH, Richard; POST, Thomas R.; SILVER, Edward A. Rational-Number 
Concepts. Em: LESH, Richard; LANDAU, Marsha (ed). Acquisition of Mathematics Concepts and Processes. New York:Academic Press, 1983.

CORBALÁN, F. Juegos Matemáticos para Secundaria y Bachillerato. Madrid: Síntesis, 1996.

GOMIDE, Cristiane G.S. O processo metodológico de inserção de jogos computacionais em sala de aula de Matemática: possibilidades do movimento de ação e reflexão da professorapesquisadora e dos alunos. Dissertação (Mestrado em Educação) - Universidade São Francisco, Itatiba, SP, 2012.

GRANDO, R.C. O jogo e a matemática no contexto da sala de aula. São Paulo: Paulus, 2004. O conhecimento matemático e o uso de jogos na sala de aula. Tese (Doutorado em Educação) - Universidade Estadual de Campinas, Campinas, São Paulo, 2000.

O jogo e suas possibilidades metodológicas no processo ensino-aprendizagem da matemática. Dissertação (Mestrado em Educação) - Universidade Estadual de Campinas, Campinas, São Paulo, 1995.

MENDES, R.M. As potencialidades pedagógicas do jogo computacional Simcity 4. Dissertação (Mestrado em Educação) - Universidade São Francisco, Itatiba, São Paulo, 2006.

MENDONÇA, M. C. D. Problematização: um caminho a ser percorrido em Educação Matemática. Tese (Doutorado em Educação) - Faculdade de Educação, UNICAMP, Campinas, SP, 1993.

MOURA, M. O. A séria busca no jogo: do lúdico na Matemática. A Educação Matemática em Revista. Revista da SBEM, ano 2, n. 3, 1994.

PACHECO NETO, E. O jogo Roller Coaster Tycoon 2 na formação dos administradores. Dissertação (Mestrado em Educação) - Universidade São Francisco, Itatiba, São Paulo, 2008.

POST, Thomas R. O Papel dos Materiais de Manipulação no aprendizado de conceitos matemáticos. Em: LINDQUIST, Mary Montgomery. Selected Issues in Mathematics Education. Tradução: Elenisa T. Curti e Maria do Carmo Mendonça. 1981.

POWELL, A.; BAIRRAL, M. A escrita e o pensamento matemático: interações e potencialidades. Coleção Perspectiva em Educação Matemática. Campinas: Papirus, 2006. 